\title{
Treadmill exercise in apparently asymptomatic aortic stenosis
}

In the absence of symptoms, the risk of sudden death in severe aortic stenosis is said to be lower than the risks associated with valve replacement. ${ }^{1-3}$ By contrast, without surgery, the median survival is 4.5 years with angina, 2.6 years with syncope, and less than 1 year with heart failure. ${ }^{4}$ The problem is that a proportion of these deaths occur early after the onset of symptoms. Unless investigation and surgery can be performed very quickly, death, whether sudden or not, is still unacceptably common in severe aortic stenosis.

The reported cumulative risk of sudden death varies between $0-9 \%,{ }^{45}$ and the figure of $6 \%$ in the article in this issue of Heart $^{6}$ does not appear unrepresentative in comparison with earlier data. ${ }^{78}$ It is possible that some of these patients had symptoms that went unrecognised, but even in studies designed with careful follow up, the mortality is $3-4 \%$ very soon after the onset of symptoms. ${ }^{5910}$ Furthermore, a mortality of $7 \%$ has been reported early on a surgical waiting list. ${ }^{11}$ Therefore, the risk of an individual patient with "presymptomatic" severe aortic stenosis dying before surgery can be performed could be as high as $12 \%$ (allowing $5 \%$ for death either suddenly or soon after the onset of symptoms and a further $7 \%$ for death on the surgical waiting list). By contrast the mortality from isolated aortic valve replacement in a fit subject should be around $1-2 \% .{ }^{12}$

\section{Surgery for "presymptomatic" aortic stenosis}

A reasonable conclusion is that patients should be offered surgery when "presymptomatic", defined, for example, by a rapid increase in gradient on serial echocardiograms". Series reporting a low risk of sudden death include many patients operated for high gradient alone or decreased exercise ability without overt symptoms, ${ }^{9}{ }^{13}$ both class IIb indications according to the American Heart Association/ American College of Cardiology guidelines. ${ }^{1}$ The division into symptomatic and asymptomatic is inevitably arbitrary since breathlessness may be non-specific and normal, or exertion limiting and clinically important. Exercise testing aids this distinction and may also predict the onset of a cardiac event.

Chest pain or dizziness occurred on exercise in 20 (30\%) patients in the study by Amato and colleagues, ${ }^{6}$ all of whom developed spontaneous symptoms during the course of follow up. We have also shown overt symptoms in a similar proportion of patients with apparently asymptomatic severe aortic stenosis. ${ }^{14}{ }^{15}$ In Amato's paper, ${ }^{6}$ exercise testing was better than echocardiographic measures of valve stenosis at predicting sudden death or the future development of symptoms. Otto and colleagues ${ }^{13}$ found the converse but included patients with less severe aortic stenosis which inevitably weighted the statistics in favour of peak transaortic velocity. However, Amato and colleagues' objective end points-ST segment depression of $2 \mathrm{~mm}$ or more and failure of the blood pressure to rise more than $20 \mathrm{~mm} \mathrm{Hg}$ during exercise-are probably too sensitive since the test was positive in most patients $(67 \%)$ and the mean time to an event was eight months. All patients with severe aortic stenosis die prematurely given a long enough follow up ${ }^{4}$ and the aim is to predict an imminent not an ultimate event. Otto and colleagues ${ }^{13}$ found that a fall in systolic blood pressure by $10 \mathrm{~mm} \mathrm{Hg}$ was a univariate predictor of progression to surgery and this may be a better threshold. It is also possible that a reproducible decline in exercise time on serial testing should be an indication for prophylactic surgery, but as yet this remains unproven.

\section{Safety of exercise testing}

Severe aortic stenosis has traditionally been regarded as a contraindication to exercise testing, and even asymptomatic moderate stenosis as a relative contraindication. ${ }^{16}$ However, testing is safe as long as it uses a protocol such as the modified Bruce, and is symptom limited. ${ }^{6}{ }^{13-15}$ Exercise should be performed if the valve area is $1.0 \mathrm{~cm}^{2}$ or less, which includes moderate as well as severe aortic stenosis. This is because the presence of symptoms depends on left ventricular function, coronary flow, and the peripheral circulation as well as the grade of valvar obstruction. ${ }^{17} 18$ Thus we showed ${ }^{14}$ that $11 \%$ of apparently asymptomatic patients with moderate stenosis (valve area $0.75-1.0 \mathrm{~cm}^{2}$ ) had symptoms on exercise testing compared with $25 \%$ with severe stenosis (valve area $<0.75 \mathrm{~cm}^{2}$ ) and none with an area above $1.0 \mathrm{~cm}^{2}$. Exercise testing should probably be repeated every six months for severe aortic stenosis and every year for moderate stenosis based on known rates of progression. ${ }^{13}$

The difference in prognosis between genuinely asymptomatic and symptomatic aortic stenosis is extreme and assessment should not be left to subjective history taking alone. Exercise testing reveals symptoms in a sizeable proportion of apparently asymptomatic patients with moderate or severe aortic stenosis and we believe should be performed routinely before assigning a patient to continued conservative treatment. The clinical use of other exercise related end points to guide prophylactic surgery is intuitively attractive but not yet established.

\section{JOHN CHAMBERS}

PAUL DAS

Valve Study Group,

Cardiothoracic Centre,

Guy's and St Thomas' Hospitals

Lambeth Palace Road

St Thomas' Hospital,

London SE1 7EH, UK

johnchambers@dial.pipex.com

1 ACC/AHA guidelines for the management of patients with valvular heart disease. A report of the American College of Cardiology/American Heart Association task force on practice guidelines (committee on management of patients with valvular heart disease). F Am Coll Cardiol 1998;32:1486-588.

2 Vaile JC, Griffith MJ. Management of asymptomatic aortic stenosis: masterly inactivity but cat-like observation. Heart 1997;78:215-17.

Otto CM. Aortic stenosis - listen to the patient, look at the valve. N Engl $\mathcal{F}$ Med 2000;343:652-4.

4 Horstkotte D, Loogen F. The natural history of aortic valve stenosis. Eur Heart f 1988;9(suppl E):57-64.

5 Pellikka PA, Nishimura RA, Bailey KR, et al. The natural history of adults with asymptomatic, hemodynamically significant aortic stenosis. $\mathcal{F}$ Am Coll Cardiol 1990;15:1012-17.

6 Amato MCM, Moffa PJ, Werner KE, et al. Treatment decision in asymptomatic aortic valve stenosis: role of exercise testing. Heart 2001;86:381-6. 
7 Ross J, Braunwald E. Aortic stenosis. Circulation 1968;38(suppl 1):61-7. 8 Frank S, Johnson A, Ross J. Natural history of valvular aortic stenosis. Br Frank S, Johnson A, R
Heart f 1973;35:41-6.

Rosenhek R, Binder T, Porenta G, et al. Predictors of outcome in severe, asymptomatic aortic stenosis. N Engl f Med 2000;343:611-7.

10 Kelly TA, Rothbart RM, Cooper CM, et al. Comparison of outcome of asymptomatic to symptomatic patients older than 20 years of age with valvular aortic stenosis. Am $\mathcal{F}$ Cardiol 1988;16:123-30.

11 Lund O, Nielsen TT, Emmertsen K, et al. Mortality and worsening of prognostic profile during waiting time for valve replacement in aortic stenosis. Thoracic Cardiovasc Surg 1996;44:289-95.

12 Lindblom D, Lindblom U, Qvist J, et al. Long-term relative survival rates after heart valve replacement. 7 Am Coll Cardiol 1990;15:566-73.

13 Otto CM, Burwash IG, Legget ME, et al. Prospective study of asymptomatic valvular aortic stenosis - clinical, echocardiographic, and exercise predictors of outcome. Circulation 1997;95:2262-70.
14 Takeda S, Rimington H, Cook B, et al. Exercise time correlates with long-axis dysfunction in apparently asymptomatic patients with aortic stenosis. Heart 1998;80(suppl):S31.

15 Das P, Rimington H, McGrane K, et al. The value of treadmill exercise testing in apparently asymptomatic aortic stenosis. I Am Coll Cardiol 2001;37(suppl A):489A.

16 Gibbons RJ, Balady GJ, Beasley JW, et al. ACC/AHA guidelines for exercise testing. A report of the American College of Cardiology/American Heart Association task force on practice guidelines (committee on exercise testing). F Am Coll Cardiol 1997;30:260-315.

17 Chambers J. Can high blood pressure mask severe aortic stenosis? fournal of Heart Valve Disease 1998;7:277-8.

18 Omran H, Fehske W, Rabahieh R, et al. Relation between symptoms and profiles of coronary artery blood flow velocities in patients with aortic valve stenosis: a study using transoesophageal Doppler echocardiography. Heart 1996;75:377-83.

\section{IMAGES IN CARDIOLOGY}

\section{A rare cause of cardiomyopathy: the systemic inflammation response syndrome (SIRS)}

We report a case of a 22 year old pregnant women seen after uterine curettage resulting from "missed abortion". The patient's condition deteriorated because of dyspnoea and leg oedema. We observed raised C-reactive protein, leucocytosis, low platelet count, and signs of disseminated intravasal coagulation. Extensive microbiological analysis did not disclose any microorganisms.

Diagnostic criteria for SIRS (systemic inflammation response syndrome)-that is, fever, tachycardia, tachypnoea, and low arterial $\mathrm{pCO}_{2}$ - were positive. We did not disclose any signs for pre-eclampsia, postpartum cardiomyopathy, antiphospholipid syndrome, or systemic lupus erythematosus.

Echocardiography showed a dilated left ventricle (end diastolic diameter $60 \mathrm{~mm}$ ) with greatly reduced global systolic left ventricular function (ejection fraction $20 \%$ ). As shown below (left), there were substantial amounts of mobile masses with cystic appearance located at the free wall of the right ventricle. Colour tissue Doppler echocardiography (below right)

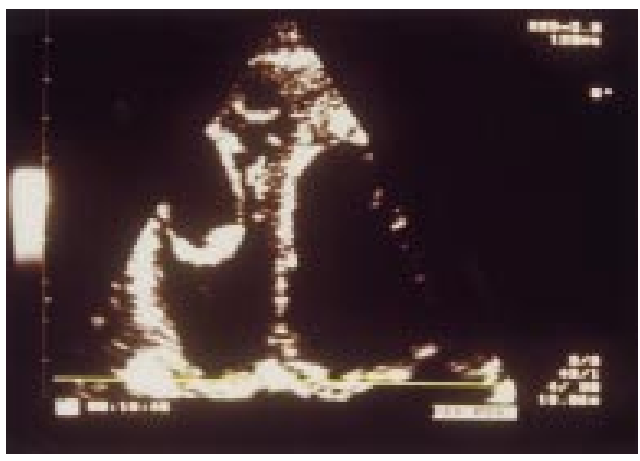

revealed an intraventricular mass moving in different directions in comparison to the adjacent myocardial walls. A ring-like cystic mass was also found in the left ventricle.

The patient was initially treated with broad spectrum antibiotics, digitalis, angiotensin converting enzyme inhibitors, diuretics, and low molecular weight heparin, followed by warfarin. The size of the right and left ventricular thrombus decreased in serial echocardiographs. Four months later thrombus formation was no longer detectable and the patient was in good condition; her ejection fraction had increased to $40 \%$ without any left ventricular enlargement.

In conclusion, we describe a case of sepsis-like syndrome after uterine curettage as a result of "missed abortion", with consecutive severe dilated cardiomyopathy and mobile biventricular thrombi.

HUBERTUS VON KORN WERNER GÜNTHER DANIEL UWE NIXDORFF hvonkorn@t-online.de

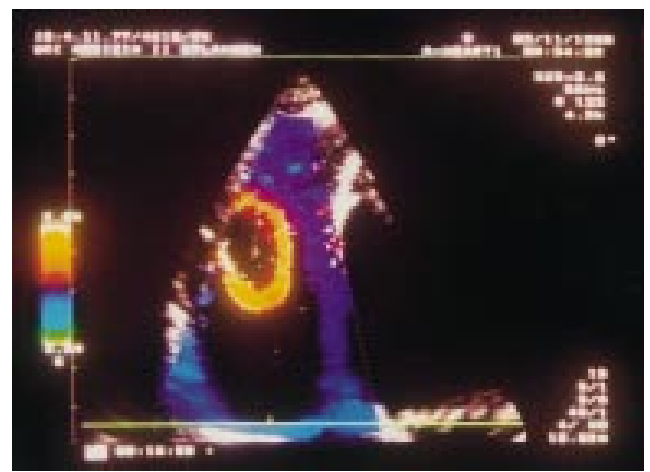

